\title{
Aleitamento materno e os motivos do desmame precoce no município de Porto Velho/RO
}

\author{
Mother breast and the reasons for early weakness in the municipality of Porto Velho/RO
}

Alegría materno y los motivos del desmame precoce en el municipio de Porto Velho/RO

Daiane Ramos de Souza ${ }^{1 *}$, Susana Miranda Diógenes ${ }^{1}$, Josimeire Souza de Oliveira Andrade, Paula Caroline Pepa Oliveira1.

\section{RESUMO}

Objetivo: Descrever os motivos que levaram a mulher ao desmame precoce de seus filhos do aleitamento materno exclusivo. Métodos: Trata-se de uma pesquisa qualitativa de caráter descritivo, exploratório. $\mathrm{O}$ estudo foi aprovado por Comitê de Ética em Pesquisa. A população desta pesquisa foi constituída por 20 mulheres que desmamaram seus filhos antes de completar seis meses de vida em uma unidade de saúde da família no município de Porto Velho. Foi aplicado um questionário com perguntas abertas para a coleta de dados, contendo 10 questões entre os dias 02 de abril ao dia 02 de maio de 2019. Resultados: Ao indagar as pesquisadas sobre o motivo pelo qual elas terem desmamado precocemente seus filhos do aleitamento materno exclusivo antes de completar seis meses de vida, seus relatos são muitos parecidos: a maioria relata que o principal motivo foi ter que voltar a trabalhar, outras referem alguns mitos sobre o leite materno, intercorrências mamárias durante a amamentação e interferências das avós no aleitamento materno. Conclusão: Conclui-se que o principal motivo para o desmame precoce em crianças menores de seis meses, foi o retorno das mães ao trabalho.

Palavras-chave: Aleitamento materno, Desmame precoce, Nutrição infantil.

\begin{abstract}
Objective: To describe the reasons that led the woman to the early weaning of her children from exclusive breastfeeding. Methods: This is a qualitative research of descriptive, exploratory character. The study was approved by the Research Ethics Committee. The population of this research was constituted by 20 women who weaned their children before completing six months of life in a family health unit in the municipality of Porto Velho. A questionnaire was applied with open questions for data collection, containing 10 questions between April 2 and May 2, 2019. Results: When inquiring the respondents about the reason why they have pre-weaned their children from exclusive breastfeeding before the age of six months, their reports are very similar: most reports that the main reason was to have to go back to work, others refer some myths about breast milk, breast intercurrences during breastfeeding, and breastfeeding interference. Conclusion: It was concluded that the main reason for early weaning in children under six months of age was the return of mothers to work.
\end{abstract}

Key words: Breastfeeding, Early weaning, Infant nutrition.

\footnotetext{
${ }^{1}$ Faculdade Interamericana de Porto Velho (UNIRON) Porto Velho/RO.

*E-mail: daianesouza905@gmail.com
}

SUBMETIDO EM: 6/2019

ACEITO EM: 7/2019

PUBLICADO EM: $8 / 2019$ 


\section{RESUMEN}

Objetivo: Describir los motivos que llevaron a la mujer al destete precoz de sus hijos de la lactancia exclusiva. Métodos: Se trata de una investigación cualitativa de carácter descriptivo, exploratorio. El estudio fue aprobado por el Comité de Ética en Investigación .A población de esta investigación fue constituida por 20 mujeres que desmamaron a sus hijos antes de completar seis meses de vida en una unidad de salud de la familia en el municipio de Porto Velho. Se aplicó un cuestionario con preguntas abiertas para la recolección de datos, conteniendo 10 preguntas entre los días 02 de abril al día 02 de mayo de 2019. Resultados: Al indagar las encuestas sobre el motivo por el cual han destetado precozmente a sus hijos de la lactancia materna exclusiva antes de cumplir los seis meses de vida, sus relatos son muchos parecidos: la mayoría relata que el principal motivo fue tener que volver a trabajar, otras refieren algunos mitos sobre la leche materna, intercurrencias mamarias durante la lactancia y las interferencias de los ave en la lactancia materna. Conclusión: Se concluye que el principal motivo para el destete precoz en niños menores de seis meses, fue el retorno de las madres al trabajo.

Palabras clave: Lactancia materna, Desmame precoz, Nutrición infantil.

\section{INTRODUÇÃO}

O aleitamento materno exclusivo é indicado para crianças até os seis meses de vida, e complementar até os dois anos de idade, sendo inclusive, fonte de todos os nutrientes e anticorpos que os bebês necessitam para concluir o seu desenvolvimento e fortalecer o sistema imunológico (ROCCI EL, FERNANDES RAQ, 2014).

Além disso, ajuda a desenvolver as habilidades orais, a formação adequada da estrutura dentária e o fortalecimento do sistema respiratório. Outro benefício, já comprovado, é o estreitamento dos laços maternos, que contribuem com as relações afetivas, emocionais e psicológicas entre mãe e filho (ROCCl EL, FERNANDES RAQ, 2014).

A endorfina presente no leite materno ajuda a amenizar a dor e reforça a eficiência das vacinas. Possui também células brancas vivas (leucócitos), anticorpos, fator bífido (impedindo a diarreia), lactofurina (impedindo o crescimento de bactérias patogênicas) (OLIVEIRA KA, 2011).

Devido às necessidades do dia a dia como o emprego, ou ainda por a comodidade, algumas mulheres param de amamentar e começam a inserir outros alimentos na alimentação da criança antes dos seis meses de vida, período em que o recomendado pelo Ministério da Saúde o aleitamento materno exclusivo (SOLDATELLI BT, et al., 2016).

As dificuldades encontradas na amamentação são elas: rachadura e fissura mamilar. $O$ mau posicionamento acarreta a má pega da mama, fazendo com que ocorra essas intercorrências podendo isso ser evitado através da técnica correta do posicionamento do bebê ao amamentar (OLIVEIRA KA, 2011).

Um dos processos inflamatórios que ocorre nas mamas durante a amamentação é a mastite, que acontece devido o esvaziamento incorreto das mamas gerando eritema, dor, febre, sendo que a mastite tem que ser tratada da forma correta para não prejudicar tanto a mãe quanto o bebê (OLIVEIRA KA, 2011).

E muito importante que o acompanhamento pré-natal e as técnicas de amamentação sejam realizados e ensinados de forma correta, assim evitando possíveis complicações mamárias e o desmame precoce. Para que o bebê abocanhe a aréola por completo e o leite seja expelido, fazendo a ejeção correta para que 0 lactente tenha um aleitamento adequado (BUENO KCVN, 2013).

A inserção de outros alimentos antes dos seis meses idade, principalmente no período em que deve haver a alimentação exclusiva por meio do aleitamento materno, influencia, de forma direta, na indução do consumo de açúcares, sódio e outros elementos, prejudicando a criança que ainda está em uma fase na qual o seu corpo ainda está em processo de desenvolvimento, favorecendo de forma significativa a queda da qualidade da saúde destas crianças, impactando na vida adulta (SOLDATELLI BE et al., 2016). 
Alvarenga SC, et al. (2018), descreve em seus estudos que, com o avanço das pesquisas na área da saúde, foi possível encontrar diversos fatores que contribuem para o adoecimento da população brasileira. Entre uma das causas para o acometimento de problemas de saúde na infância e, que podem refletir na vida adulta, é o desmame precoce e a inserção da alimentação complementar antes dos seis meses de idade.

O desmame precoce no aleitamento materno é uma questão de saúde pública, pois pode desencadear inúmeros problemas de saúde na vida da criança, os quais poderiam ser prevenidos com o simples ato de amamentar. A enfermagem possui grande importância na educação em saúde, podendo minimizar, por meio de intervenções da consulta de enfermagem e educação em saúde, o percentual de mulheres que deixam de amamentar o recém-nascido antes dos seis meses (ALVARENGA SC, et al., 2018).

O profissional de enfermagem é o principal ator das intervenções que visam à prevenção de agravos e a promoção em saúde, executando intervenções, programas e ações que busquem promover na população a educação em saúde (SOUSA F, et al., 2019).

Estudos sugerem que o aleitamento materno contribui não somente para a saúde da mulher, beneficiando na recuperação do peso anterior a gestação, na produção de compostos que influenciam positivamente no corpo da mulher, mas também no fortalecimento do afeto entre mãe e filho (ALVARENGA SC, et al., 2018).

$O$ ato de amamentar é um ato que necessita de dedicação, tempo e paciência por parte da mulher. Muitos fatores estão associados ao desmame precoce no aleitamento exclusivo. As mulheres da pós - modernidade possuem paciência incipiente para se dedicar ao aleitamento, bem como querem buscar alternativas para evitar estarem inteiramente à disposição da criança, adquirindo o hábito de inserir chupetas e mamadeiras, prejudicando com isso o aleitamento materno. (OLIVEIRA CS, et al., 2015).

Este estudo justificou-se pela importância ao aleitamento materno, dos seus benefícios à saúde da mulher e do bebê e do suporte teórico com a finalidade de embasar as orientações em saúde, as intervenções necessárias com as mães em período do aleitamento materno, bem como de outros atores presentes nesse momento da vida destas mulheres.

\section{MÉTODOS}

Estudo de campo, do tipo descritivo, com abordagem qualitativa, realizado na Unidade Saúde da Família Doutor José Adelino da Silva, localizada no setor Leste do município de Porto Velho-RO.

A instituição de saúde conta com cinco equipes de saúde da família, sendo cinco médicos, cinco enfermeiras, vinte e três agentes comunitários de saúde, cinco dentistas e atende a sete mil e duzentas famílias de diversas áreas cobertas e descobertas pela rede. O local da pesquisa foi escolhido devido ao fato de atender um número expressivo da população e ser de fácil acesso nas proximidades de nossas residências. A população desta pesquisa foi constituída por mulheres que desmamaram seus filhos antes de completar seis meses de vida, na qual foi aplicado um questionário com 10 perguntas abertas.

A amostra foi selecionada aleatoriamente por conveniência no dia do grupo de puericultura e planejamento reprodutivo composto por 20 mulheres. A unidade possui 5 equipes de saúde da família, sendo 3 no período matutino e 2 no período vespertino, cujo instrumento foi aplicado a 4 mulheres de cada equipe.

Todos os princípios éticos e legais foram respeitados pelos pesquisados e o projeto foi sujeito à aprovação pelo Comitê de Ética em Pesquisa (CEP). Somente após a sua aprovação pelo CEP Com Parecer: 3.234.559 no dia: 30 de março de 2019, a coleta de dados teve início entre os dias 02 de abril a 02 de maio de 2019. De acordo com a Resolução N466, de 12 de dezembro de 2012, do Conselho Nacional de Saúde, foi obrigatória a assinatura do TCLE pelo colaborador da pesquisa para que as suas informações pudessem fazer parte dos resultados. Durante a pesquisa foi considerado os aspectos éticos presentes na Resolução No 510, de 7 de abril de 2016, do Conselho Nacional de Saúde.

A convidada teve o livre arbítrio para participar da pesquisa, e esta informação estava contida no TCLE. A participante da pesquisa rubricou todas as folhas do TCLE, e assinou na última página do referido termo. 


\section{RESULTADOS E DISCUSSÃO}

Ao indagar as pesquisadas sobre o motivo pelo qual elas terem desmamado precocemente seus filhos do aleitamento materno exclusivo antes de completar seis meses de vida, seus relatos são muitos parecidos: a maioria relata que o principal motivo foi ter que voltar a trabalhar, outras referem alguns mitos sobre o leite materno, intercorrências mamárias durante a amamentação e interferências das avós no aleitamento materno.

\begin{tabular}{ll} 
Tabela 1 - Perfil Sócio demográfico. \\
\hline Mulheres Entrevistadas: & 20 \\
\hline Idade: & 27 a 44 anos \\
Empregadas: & 16 \\
Desempregadas: & 4 \\
Nível Fundamental: & 4 \\
Nível Médio: & 13 \\
Nível Superior: & 3 \\
Renda familiar: $\quad 980$ a 3.000 &
\end{tabular}

Fonte: SOUZA DR, DIOGENES SM 2019.

Garantimos o anonimato dos entrevistados, os nomes ficaram no sigilo, através do uso de pseudônimos sendo definidos por letras e número sendo: M1, M2, M3, M4, M5, M6, M7, M8, M9, M10. Dessa forma o pesquisador pode desenvolver conceitos, opiniões a partir da análise de conteúdo encontradas nas respostas dadas pelos participantes da pesquisa.

\section{Desmame devido o retorno ao trabalho}

A mulher moderna é sobrecarregada, enfrentando diversos obstáculos na maternidade, como conciliá-la com o trabalho, os estudos, os afazeres domésticos, outros filhos, o autocuidado e tentar realizar ainda uma atividade de lazer. Sabe-se que a maternidade é cercada por mitos e verdades, expectativas e ansiedade, momentos de alegria e tristeza, e que por vezes essa "nova mulher" contemporânea mostra-se apreensiva e com dificuldades em assimilar o papel materno, favorecendo o desmame precoce. Nessa cascata de acontecimentos, a interrupção precoce do aleitamento materno, ou seja, antes dos seis meses de idade do bebê, pode impactar negativamente na qualidade de saúde da criança. (SCHINCAGLIA RM, et al., 2015).

Das vinte (20) mulheres, apenas dez (10) afirmam que tiveram atividades de educação em saúde sobre a importância do aleitamento materno exclusivo, por um profissional de saúde durante a realização do pré-natal.

Os resultados deste estudo mostram que a volta ao trabalho foi o primeiro fator predominante para o desmame precoce. Das mulheres pesquisadas, a maioria nos relataram sobre esse motivo conforme descrito a seguir:

$$
\text { "Voltei a trabalhar". (M1) }
$$

"Acabou minha licença maternidade". (M19)

O enfermeiro, por meio de estratégias pode trabalhar com o aleitamento materno visando evitar o desmame precoce, tanto por meio da consulta de enfermagem no pré-natal ou no acompanhamento puerperal, visando contribuir com o aumento do conhecimento ou fortalecimento sobre a temática (COSTA EFG, et al., 2018).

O desmame precoce surge diante de alguns problemas sociais, mas também é uma consequência da modificação do perfil da mulher moderna. As mulheres estão mais presentes no mercado de trabalho, tendo que dividir o seu tempo entre o trabalho, às atividades domésticas e cuidados com os filhos. Muitas vezes, a mulher não consegue conciliar todas suas atividades diárias, e passa a pensar em formas alternativas, dentre elas a interrupção da amamentação exclusiva, já que tal atividade requer tempo e dedicação (SOLDATELLI BE, et al., 2016). 
O resultado confirma o que dizem algumas pesquisas de artigos científicos que apresentam um grande índice aos resultados do fato de ter que voltar ao trabalho. (SOLDATELLI BE, et al., 2016). De acordo com a nossa pesquisa, a forma que mais facilitaria quanto à maior durabilidade da amamentação, seria elas não trabalhassem fora de casa pois, às vezes, o fim da licença maternidade coincide com o término do período de aleitamento materno exclusivo (AME) ou dependendo da empresa se ela e privada ou pública.

\section{Mitos sobre o leite materno}

A introdução de alimentos precocemente ao lactente é explicada por contextos culturais, envolvendo mitos e crenças. "Leite fraco", "pouco leite" são expressões relatadas por muitas mães que demonstram insegurança quando o assunto é amamentação, o que pode resultar na introdução precoce de outros alimentos, e oferta de chupeta, e mamadeiras que mesmo não sendo fator principal na interrupção do Aleitamento Materno; é apontado como sendo capaz de antecipar o desmame (VIEIRA TO, et al., 2014).

Segundo Vieira TO, et al. (2014) Os resultados deste estudo corroboram com as evidências da literatura, que são: leite fraco, e pouco leite ou seja, muitas mães interrompem o aleitamento materno exclusivo por acreditar que seu leite é insuficiente e fraco de acordo como está descrito pelas pesquisadas:

"Ele mamava muito, nunca estava cheio" (M2)

"Chorava muito e sempre querendo ficar no peito, me dava agonia" (M10)

É necessário entender que em alguns momentos, a mãe não quer amamentar e tentar justificar a interrupção do aleitamento dizendo que o leite e fraco ou insuficiente para saciar a fome do bebê, sendo essa a sua justificativa para esta atitude (VIEIRA TO, et al., 2014).

As pesquisas nos mostram que o mito do leite fraco é algo cultural entre as mulheres que já amamentaram, porém sabe-se que isso é um ato capaz de prejudicar o crescimento do bebe, pois o leite materno é suficiente para saciar e suprir a fome do lactente; o que ocorre e que elas não obtiveram conhecimento suficiente quanto a importância do Aleitamento Materno (ROCCI EL, et al., 2014)

Estudos realizados comprovam os reais benefícios do leite materno durante a amamentação, também sabemos que outros alimentos são inseridos durante a amamentação por essas mães, não sabendo o quanto é desfavorável para o lactente, por serem prejudiciais a sua fisiologia. $O$ fato de muitas mães acharem que o seu leite é insuficiente para saciar a fome do bebê, as induz a incluir outros alimentos (AMARAL LJX. et al., 2015).

\section{Intercorrências mamárias durante a amamentação}

Os problemas mamários estão dentre as principais causas que levam a prática do desmame precoce. 0 tipo de mamilo influencia essa prática, embora não as impeçam. As mudanças relacionadas à mama da puérpera podem ser revertidas com alguns métodos adequadas de pega (VIDUEDO AFS, et al.,2015). A seguir a fala de algumas delas nos comprovam isso;

"Eu sentia muita dor quando ele mamava, chorava de dor, foi bem doloroso, o bico do meu peito era pra dentro" (M3).

"Ela mamava o dia todo, meus peitos nunca saravam, dei mamadeira, porque não aguentava mais a dor" (M14).

O êxito para uma boa amamentação necessita de preparo e conhecimento sobre aspectos anátomo fisiológicos, posições e métodos corretos de amamentação e cuidados preventivos com a mama. Durante a gestação, o preparo das mamas para a função lactogênica deve ser ressaltado, assim como orientações de educação em saúde pelos profissionais da saúde (AZEVEDO ARR, et al., 2015)

O preparo das mamas apresenta grande importância no ato da amamentação, tranquilizando a mulher por meio do exame da mama, passando informações quanto à possibilidade de amamentar, independentemente do tipo da mama, contribuindo dessa forma para uma estratégia eficaz de prevenção das complicações mamárias (DRANSKI CR, et al., 2010). 
O trauma mamilar causa desconforto e dor na lactante prejudicando a amamentação exclusiva e ocasionando a oferta de outro alimento ao bebê, o que também pode resultar na baixa produção de leite ou até parar a produção do mesmo. Diante deste fato o bebê pode confundir os bicos e demonstrar desinteresse na mama levando ao desmame precoce (MORAES BA, et al., 2016)

\section{Interferências das avós maternas no aleitamento}

As mulheres enfrentam grandes interferências pelos hábitos familiares e crenças, devido à deficiência de informações recebidas por meios de profissionais da saúde. Isso caracteriza uma necessidade de se elaborar um método educativo de forma participativa, contínua e organizada do período gestacional e se estendendo até o pós-natal tardio, a fim de capacitar essas mulheres para que venham serem mães mais determinadas e detentoras dos conhecimentos fundamentais para dar continuidade ao aleitamento materno (VIEIRA TO, et al., 2014).

No âmbito familiar, a nutriz executa um processo de escolha de um membro familiar como referência de apoio. Geralmente essa pessoa é um membro mais velho, que tenha passado por essa experiência maternal, como a mãe, a avó, ou irmã, mas dependendo do grau de instrução desta pessoa podendo ser favorável ou desfavorável ao aleitamento materno exclusivo (TEIXEIRA MA, et al., 2011). Foi o que os depoimentos delas nos revelaram;

\footnotetext{
"Meu bebê chorava muito com cólicas, aí minha mãe me orientou eu dar chá para ele, pois iria aliviar as cólicas. No entanto não parei mais de dar chá caseiro pra ele e ate água comecei a ofertar" (M20)

"Fui mãe muito cedo eu não sabia como era criar um filho, a minha mãe me ajudou na criação da minha filha, a minha bebê era muito chorona ai minha mãe reclamava que meu leite não estava sustentando a fome do neném, daí ela me orientou a dar outro leite para complementar o meu" (M17)
}

A figura da avó materna se representa como um fator desfavorável para o prosseguimento do aleitamento materno, essencialmente o exclusivo. Elas trazem seus conhecimentos por meio da herança cultural, onde são resguardadas pelo entendimento empírico de seus antecedentes e visa com sua sabedoria, baseada. No senso comum, a repassarem esses ensinamentos as suas filhas. Portanto, as orientações dadas por elas contrariar as evidências científicas mais convenientes a serem praticada pelas mães, em relação à amamentação e ao cuidado com seu bebê (FERREIRA TDM, et al., 2018).

A possibilidade de uma criança estar em aleitamento materno exclusivo nos primeiros meses, decresceu à medida que estende os dias de vida. Esta consequência acaba sendo prevista, uma vez que são costumes frequentes, como o uso de chás, sucos, leite artificial e água $O$ aleitamento materno padece uma queda do quarto para o quinto mês de vida da criança (53,7\%) (SOUZA SNDH, et al., 2012). A inclusão de líquidos inicia a aumentar a partir de 30 dias de vida do bebê (FIGUEREDO SF, et al., 2013).

As puérperas são influenciadas de forma negativas pelas mães e avos quando o assunto e amamentar, devido o fato de algumas delas não terem sido bem-sucedidas em seu histórico de amamentação, muitas vezes pela falta de informação quanto a importância do aleitamento materno. Todavia as avós geralmente estão sempre presentes durante o período puerperal e chegam a influenciar as puérperas na introdução de outros alimentos o que nos prova que elas são influenciadoras pelas suas próprias experiências (OLIVEIRA CS, et al., 2015).

\section{CONCLUSÃO}

Diante deste estudo, pode-se atribuir como o principal motivo para o desmame precoce em crianças menores de seis meses, o retorno das mães ao trabalho, segundo alguns relatos; percebe-se que outros motivos, não menos relevantes, as fizeram optar pelo desmame precoce, como por exemplo: achar que 0 leite do seio era fraco e não sustentava o bebê; as fissuras mamilares; e a influência direta da mãe (avó) na 
decisão de não amamentar. Espera-se que através desse estudo os profissionais de saúde da família da USF reflitam a respeito de suas práticas e busquem soluções estratégicas e subsídios para incentivar e monitorar mais precisamente de perto as mulheres cujos filhos têm idade inferior a seis meses. Sabe-se da importância das atividades de educação e saúde para o incentivo ao aleitamento materno exclusivo, consequentemente evitando o desmame precoce. Sendo que a reflexão sobre a importância do aleitamento materno exclusivo até os seis meses de vida para o crescimento e desenvolvimento de seu filho, é que as futuras mães e puérperas podem aderir a esta prática que é comprovadamente a mais saudável.

\section{REFERÊNCIAS}

1. ALVARENGA SC, CASTRO DS, LEITE FMC et al. Critical defining characteristics for nursing diagnosis about ineffective breastfeeding. Rev Bras Enferm [Internet]. 2018;71(2):314-21.

2. AMARAL LJX, SALES SS, CARVALHO DPSRP et al. Fatores que influenciam na interrupção do aleitamento materno exclusivo em nutrizes. Rev Gaúcha Enferm. 2015;36(esp):127-34.

3. AZEVEDO ARR, ALVES VH, SOUZA RMP et al. O manejo clínico da amamentação: saberes dos enfermeiros. Escola Anna Nery Revista de Enfermagem 19(3) Jul-Set 2015.

4. BUENO KCVN. A importância do aleitamento materno exclusivo até os seis meses de idade para a promoção de saúde da mãe e do bebê 2013. 28 f. Trabalho de Conclusão de Curso (Especialização em Atenção Básica em Saúde da Família) lu2013 Universidade Federal de Minas Gerais, Campos Gerais, 2013.

5. COSTA EFG, ALVES VH, SOUZA RMP et al. Atuação do enfermeiro no manejo clínico da amamentação: estratégias para o aleitamento materno. Rev Fund Care Online. 2018 jan./mar.; 10(1):217-223.

6. DRANSKI CR, MENON K, LEMOS JRD et al. Consulta de enfermagem: Frequência de problemas mamários no período puerperal. 2010.

7. FERREIRA TD, PICCIONI LD, QUEIROZ PH, et al. Influência das avós no aleitamento materno exclusivo: estudo descritivo transversal. einstein (São Paulo). 2018;16(4):eAO4293.

8. FIGUEREDO SF, MATTAR MJG, ABRÃO ACFV. et al. Hospital amigo da criança: prevalência de aleitamento materno exclusivo aos seis meses e fatores intervenientes. Rev Esc Enferm USP, 2013, 47(6):160-171.

9. MORAES BA, GONÇALVES AC, STRADA JKR et al. Fatores associados à interrupção do aleitamento materno exclusivo em lactentes com até 30 dias. Rev. Gaúcha Enferm. vol.37 no.spe Porto Alegre 2016 Epub July 20, 2017

10. OLIVEIRA KA. Aleitamento materno exclusivo até seis meses de vida do bebê: benefícios, dificuldades e intervenções na atenção primária de saúde. Universidade Federal de Minas Gerais. Faculdade de medicina núcleo de educação em saúde coletiva Conselheiro Lafaiete, 2011.

11. OLIVEIRA CS, IOCCA FA, CARRIJO MLR, et al. Amamentação e as intercorrências que contribuem para o desmane precoce. Revista Gaúcha de Enfermagem. v. 36. 2015.

12. ROCCI EL, FERNANDES RAQ. Dificuldades no aleitamento materno e influência no desmame precoce. Rev. bras. enferm., Brasília, v. 67, n. 1, p. 22-27, Feb. 2014.

13. SCHINCAGLIA RM, OLIVEIRA AC, SOUSA LM et al. Práticas alimentares e fatores associados à introdução precoce da alimentação complementar entre crianças menores de seis meses na região noroeste de Goiânia. Epidemiol. Serv. Saúde, Brasília, v. 24, n. 3, p. 465-474, set. 2015

14. SOLDATELLI BE, VIGO AL, GIUGLIANI ERJ et al. Adherence to dietary recommendations for preschoolers: clinical trial with teenage mothers. Revista de Saúde Pública, São Paulo, v. 50, p. 83, jan. 2016. ISSN 15188787

15. SOUZA SNDH, MIGOTO MT, ROSSETTO EG et al. Prevalência de aleitamento materno e fatores associados no município de Londrina-PR. Acta Paul. Enferm, 2012, 25(1):29-35

16. SOUSA AF, CLARO ML, SOUSA AL et al. Avanços e desafios do aleitamento materno no Brasil: uma revisão integrativa. Revista Brasileira em Promoção da Saúde. v. 28, n. 3. 2015

17. TEIXEIRA MA, NITSCHKE RG, SILVA LWS et al. A prática da amamentação no cotidiano familiar - um contexto intergeracional: influência das mulheres-avós. Revista Temática Kairós Gerontologia, 14(3), ISSN 2176-901X, São Paulo, junho 2011: 205-221.

18. VIDUEDO AFS, LEITE JRC, MONTEIRO JCS et al. Severe lactational mastitis: particularities from admission. Rev Bras Enferm. 2015;68(6):806-11.

19. VIEIRA TO, VIEIRA GO, OLIVEIRA NF et al. Duration of exclusive breastfeeding in a Brazilian population: new determinants in a cohort study. BMC Pregnancy Childbirth. 2014; 14:175. 